\title{
中国南方传统木构建筑典型榫卯节点抗震性能 试验研究
}

\author{
淳庆 $^{(1 *}$ ，乐志 ${ }^{11}$ ，潘建伍 ${ }^{2}$ \\ (1) 东南大学城市与建筑遗产保护教育部重点实验室, 南京 210096; \\ (2) 南京航空航天大学土木系, 南京 210016 \\ *E-mail: cqnj1979@163.com
}

收稿日期: 2010-10-02; 接受日期: 2011-04-01

国家自然科学基金(批准号: 51008059)和中国博士后特别基金(批准号: 201003543)资助项目

摘要 对中国南方传统木构建筑典型榫卯节点的抗震性能进行了研究. 其中包括: 燕尾榫(含下落式燕尾蟭)、半榫、十字䇫头榫以及馒头榫 4 种典型椎卯节点, 共进行 了 13 个试件的低周反复荷载试验研究. 通过试验获取这 4 种典型榫卯节点在水平荷 载作用下的破坏模式、滞回曲线、骨架曲线以及转角刚度. 研究结果可为中国南方传 统木构建筑的抗震性能研究和修缮加固提供理论基础.

关键词

中国南方传统木构建筑

榫卯节点

抗震性能

转角刚度

\section{1 前言}

木结构是人类建筑史上应用时间最长的建筑材 料之一, 已有数千年的应用历史, 在我国现存的古建 筑中, 木结构和砖木混合结构占有相当大的比例. 作 为中国历史文化的瑰宝, 由于长期的风雨侵蚀、战 争、地震的破坏, 材料和结构性能不可避免的减弱和 损伤, 大量传统木构建筑已出现险情, 对其维修保护 的要求日益迫切. 例如, 在 2008 年汶川地震中, 传统 木构建筑损毁较严重, 其中包括: 世界文化遗产— 都江堰二王庙、青城山道教古建筑群、李白故居、杜 甫草堂等. 因此, 综合考虑历史性、艺术性和科学性, 对这些传统木构建筑的抗震性能进行科学研究, 为 维修和保护提供科学依据, 已是当务之急.

近年来, 国内一些学者陆续开始对中国传统木 构建筑抗震性能进行研究. 俞茂宏等人 ${ }^{[1,2]}$ 通过定义
和引入反映木结构古建筑榫卯节点特性的半刚性节 点单元, 建立了有限元模型并进行了动力分析. 姚㑆 等人 ${ }^{[3]}$ 展开了中国古代建筑木构体系的静力与动力 研究, 通过宋营造法式等典型实物等比例模型的试 验, 在传统木构建筑静力分析及抗震分析中进行数 据积累与近似计算. 薛建阳等人 ${ }^{[4]}$ 则通过殿堂型木构 模型振动台试验研究了其动力特性和地震反应，指 出木构榫卯连接的柔性和挤压变形是结构耗能减震 的主要原因. 高大峰等人 ${ }^{[5 \sim 7]}$ 通过对木构架模型在水 平反复荷载作用下的试验研究, 分析与探讨了中国 古代木结构在相应状态下的变形及受力特征及其榫 卯节点工作机制, 通过对榫卯节点的转动弯矩与相 应转角试验数据的分析与研究, 确定了榫卯节点的 转动刚度, 提出了该类型结构在水平地震荷载作用 下的计算模型，为中国古建木构架在水平地震作用 下的抗震分析提供了一种可资借鉴的方法. 葛鸿鹏 ${ }^{[8]}$

英文版发表信息： Chun Q, Yue Z, Pan J W. Experimental study on seismic characteristics of typical mortise-tenon joints of chinese southern traditional timber frame buildings. Sci China Tech Sci, 2011, 54: 2404-2411, doi: 10.1007/s11431-011-4448-3 
从古建筑的结构体系、结构布局、造型和构造入手, 通过木构架模型在水平反复荷载作用下的试验研究, 对榫卯工作机制、破坏模式和抗震性能进行了分析. 谢启芳等人 ${ }^{[9,}$ 10]进行了未加固木构架和加固木构架 在水平低周反复荷载作用下的试验研究, 得到了各 个木构架的破坏特征、滞回曲线、骨架曲线、强度和 刚度退化规律、变形及耗能等性能, 在此试验的基础 上建立了木结构构架的恢复力模型.

在国外，Villar 等人 ${ }^{[11]}$ 对木构件之间的节点进行 有限元模拟，指出构件接触面间的摩擦作用对抗震 很重要，同时构件间的角度对接触面上的应力分布 有影响. Dina 等人 ${ }^{[12]}$ 对台湾 Die-Dou 木构进行有限元 模拟，指出节点的刚度对结构整体在地震作用下的 位移响应有很大影响, 通过节点试验指出, 坚向荷载 对节点的转角刚度有影响.

综上所述, 国内研究主要针对北方传统木构体 系而言, 研究对象均依据宋营造法式, 构件粗大, 榫 卯节点主要选用燕尾榫和直榫 2 种, 较为单一. 国外 研究主要针对当地特有的木构体系. 目前研究均未 能反映出以穿斗体系和营造法原形式为主的中国南 方传统木构建筑受力机理.

\section{2 试验设计}

为了解中国南方传统木构的抗震性能，通过试 验对典型榫卯节点的抗震性能进行研究. 针对南方 传统木构榫卯的各种作法, 在参考《营造法原》和现 场实际调查的基础上, 归纳为 4 种基本榫卯种类, 包 括燕尾榫、十字箱头榫、半榫和馒头榫 4 类, 如图 1 所示. 燕尾榫为梁头插入柱顶印口, 插入榫头按 $1: 10$
收溜; 下落式燕尾榫为燕尾榫不在柱头位置的变种, 即通过开大口，插入燕尾榫和垫块的方式使得燕尾 榫可以置于柱头以下的任意位置; 十字滗头榫为传 统木结构角部常见榫卯, 2 个方向的梁头成 $90^{\circ}$ 相交, 互相卡接; 半榫为南方穿斗式穿枋结构中常见榫卯, 两梁头各出约半柱径穿透柱子; 馒头榫为抬梁式专 用, 从柱头出榫插入梁底.

为了体现榫印的地域特征各种榫卯均有 2 种或 以上的作法变化: 燕尾榫包括榫长加长, 榫宽加宽和 下落式变异作法 3 种作法; 十字䈐头榫包括榫宽加宽 和加木销 2 种作法; 半榫包括榫宽加宽和榫高变小 2 种作法; 馒头榫包括榫截面加大和榫长加大 2 种作法. 这些作法差异可以帮助推导不同地域榫卯作法造成 的节点刚度的差异，具体榫卯尺寸详见表 1 .

为了得到较真实的榫卯节点抗震性能, 试验方 案均为构架化榫卯, 即不仅把榫印作为实际梁柱交 接的节点研究, 还同时研究构架的性能与结构行为, 所有构件按 $1: 2$ 缩尺后组成高 $1.5 \mathrm{~m}$, 跨度 $1.5 \mathrm{~m}$ 的单 榀框架. 其中柱径为 100 120 mm, 梁尺寸为 $80 \mathrm{~mm}$ $\times 120 \mathrm{~mm}$.

本次试验用材选用同一批次的杉木，通过材性 试验得到其力学参数：顺纹抗拉强度 $61.3 \mathrm{MPa}$, 顺纹 抗压强度 $38.3 \mathrm{MPa}$, 抗弯强度 $103.3 \mathrm{MPa}$, 顺纹抗剪 强度 3.6 MPa，抗弯弹性模量 $9482 \mathrm{MPa}$.

试验的方法为低周反复水平加载, 试验设计 4 组 共计 13 个构件, 使用水平反力架加载模拟水平荷载, 使用千斤顶坚向加载模拟坚向荷载, 施加坚向力的 千斤顶能随试件水平位移而移动，从而使坚向力的 作用线总是与地面垂直. 其中燕尾榫试件的编号为 $\mathrm{KJ} 1$ ，其非下落式 3 种作法分别为 KJ1-1, KJ1-2, KJ1-3,

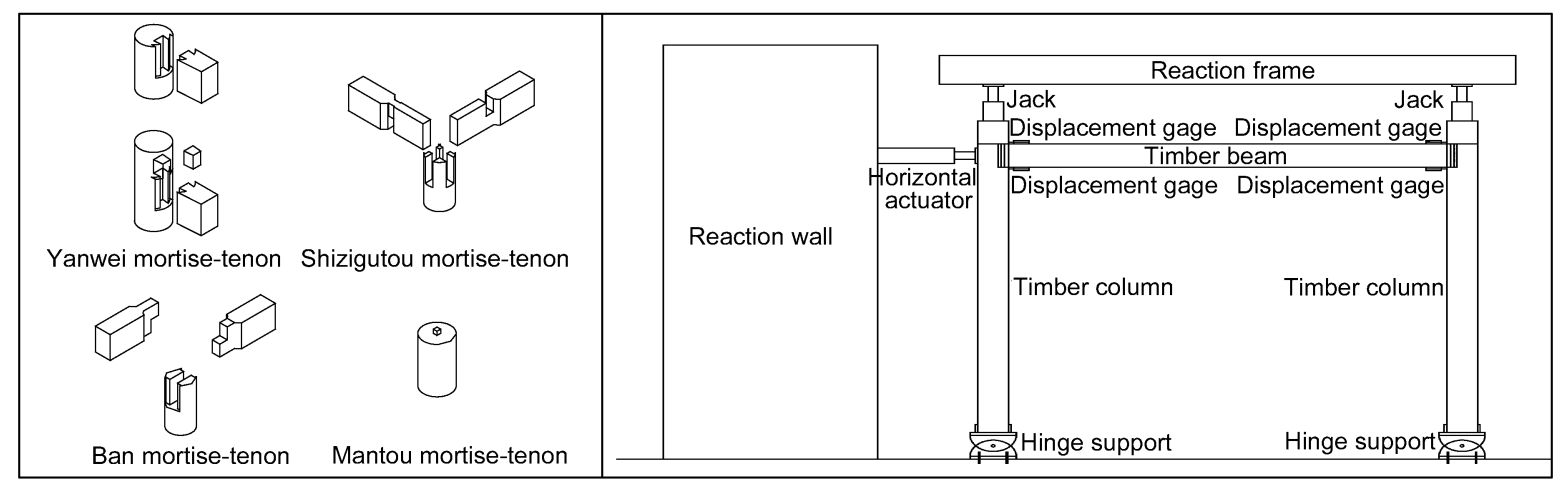

图 1 典型榫卯节点试验设计 


\section{表 1 榫卯实验尺寸表}

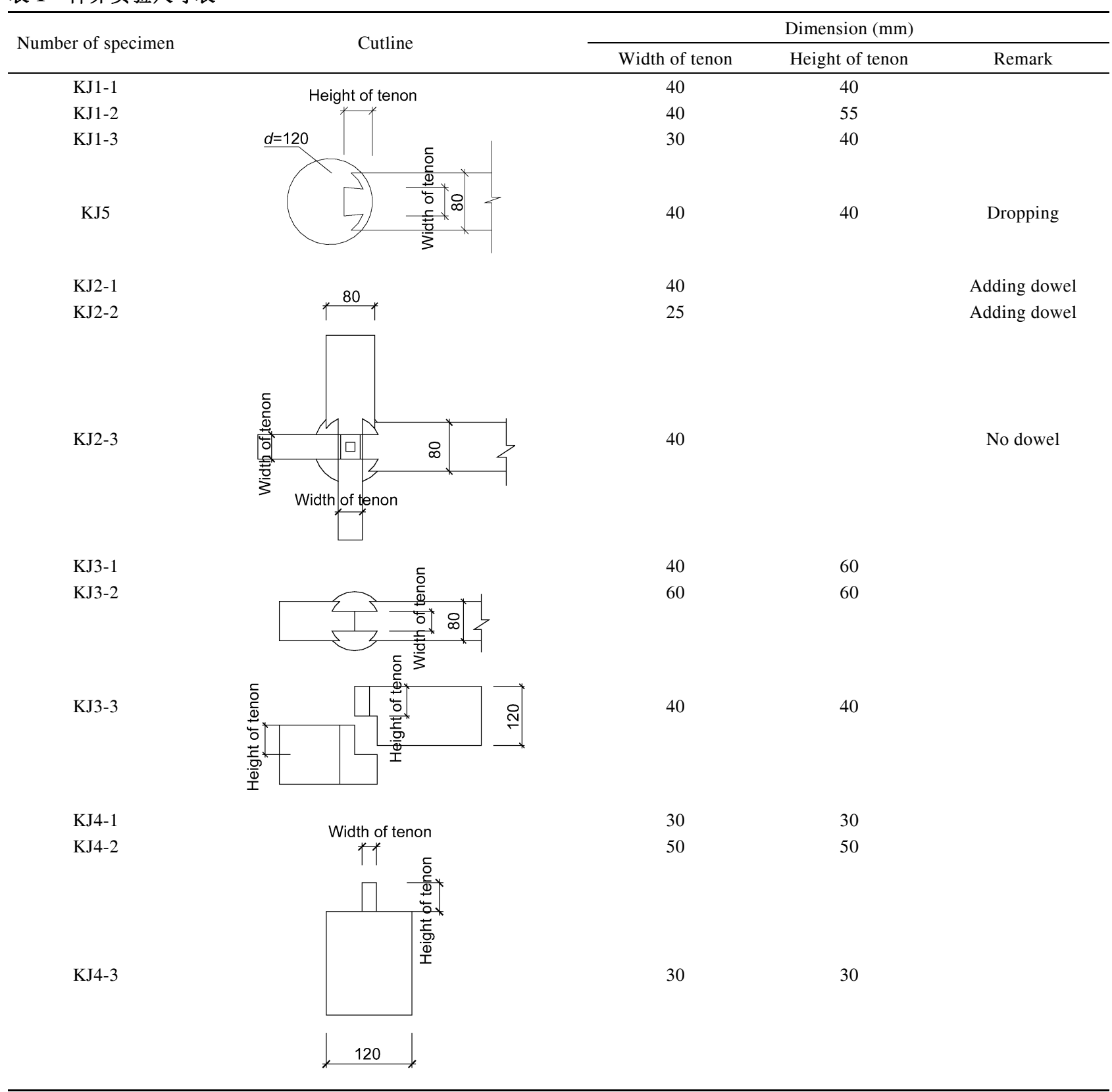

下落式燕尾榫编号 $\mathrm{KJ} 5$; 十字䈐头榫编号分别为 $\mathrm{KJ} 2-1, \mathrm{KJ} 2-2, \mathrm{KJ} 2-3$; 半榫为 $\mathrm{KJ} 3-1, \mathrm{KJ} 3-2, \mathrm{KJ} 3-3$; 馒 头榫为 KJ4-1, KJ4-2, KJ4-3. 构架所受坚向荷载按照 真实结构荷重结合缩尺比例, 施加坚向荷载 $20 \mathrm{kN}$. 同时确定以位移作为控制指标. 第一级加载位移为 $20 \mathrm{~mm}$, 以后每增加 $20 \mathrm{~mm}$ 作为下一级位移, 循环 加载直至到达构件破坏. 试验时, 通过水平加载装置 测得水平力及水平位移, 坚向加载装置测得坚向力,
位移计测得左右榫头上下的拔榫量. 本次试验部分 构件如图 2 所示.

\section{3 试验现象}

\section{1 燕尾榫}

$\mathrm{KJ} 1$ 组和 $\mathrm{KJ} 5$ 组为燕尾榫, 从试验现象看, 燕尾 榫节点构架在水平荷载下的破坏过程先是榫头挤紧 

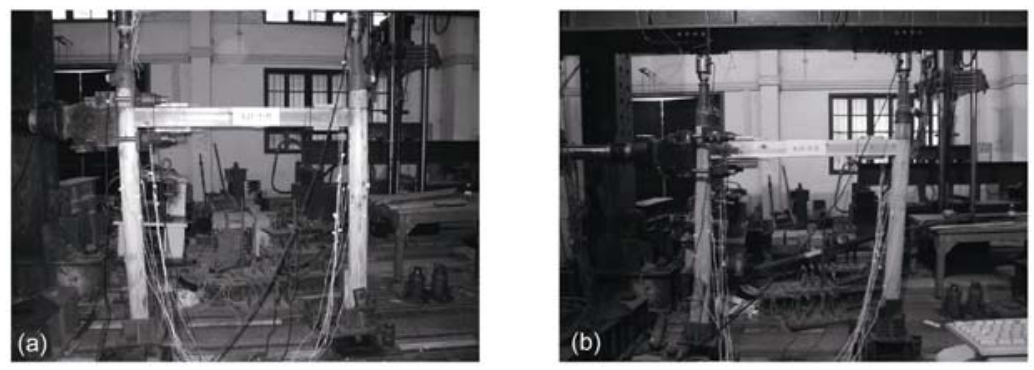

图 2 试验构件

(a) KJ1-1; (b) KJ1-2

发出吱吱声，随后是榫的收溜破坏并伴随柱卯口出 现垂直裂纹, 最后是拔榫破坏. 在各作法中, 加长型 燕尾榫破坏最晚, 变窄型次之, 标准型最先破坏. 燕 尾榫构架的极限水平位移为 160 220 mm. 图 3 为燕 尾榫节点的最终破坏形态.

\section{2 十字䈨头榫}

$\mathrm{KJ} 2$ 组为十字箍头榫, 各分组作法不同, 从试验 现象看, 其破坏过程先是榫头挤紧发出吱吱声, 随后 很快出现明显且不可恢复的梁柱相对转动变形并快 速增大, 柱卯和梁榫分离, 变形原因主要是柱端印口 变形, 最后为榫卯根部破坏. 通过减小梁榫的宽度或 增设销钉可以延后破坏.十字箍头榫构架的极限水
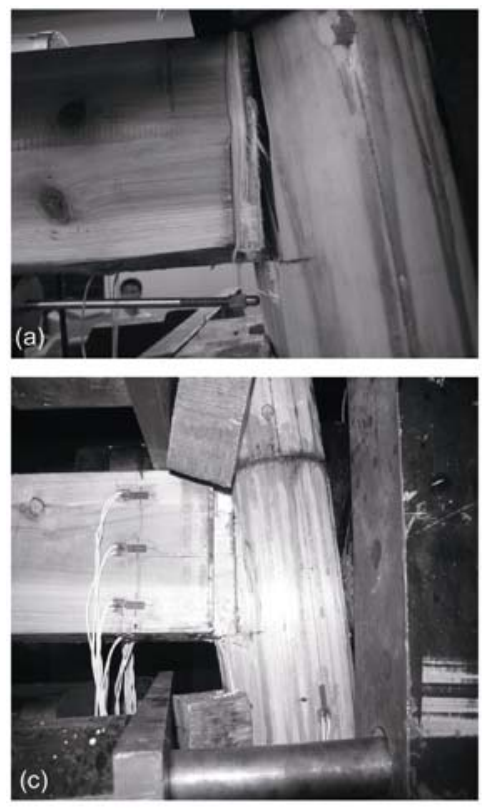

图 3 燕尾榫节点破坏形态

(a) KJ1-1 破坏形态; (b) KJ1-2 破坏形态; (c) KJ1-3 破坏形态; (d) KJ5 破坏形态

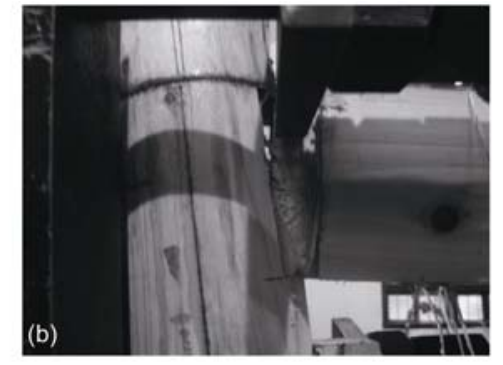

平位移为 100 160 mm. 图 4 为十字䉗头榫节点的最 终破坏形态.

\section{3 半榫}

$\mathrm{KJ} 3$ 组均为半榫, 各分组作法不同, 从试验现象 看, 其破坏过程先是榫头挤紧发出吱吱声, 随后柱梁榫 印脱开, 并伴随着柱端出现坚向裂缝, 这一变化逐渐加 剧, 最后为卯口折断破坏. 增加梁宽或减少梁榫头长 度不会显著改变破坏阶段. 半榫构架的极限水平位 移为 160 180 mm. 图 5 为半榫节点的最终破坏形态.

\section{4 馒头榫}

$\mathrm{KJ} 4$ 组均为馒头榫，各分组作法不同，从试验现

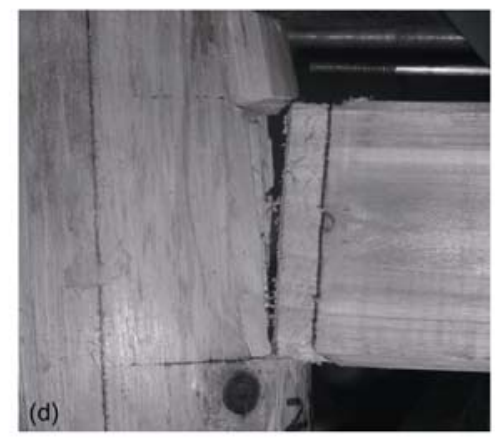



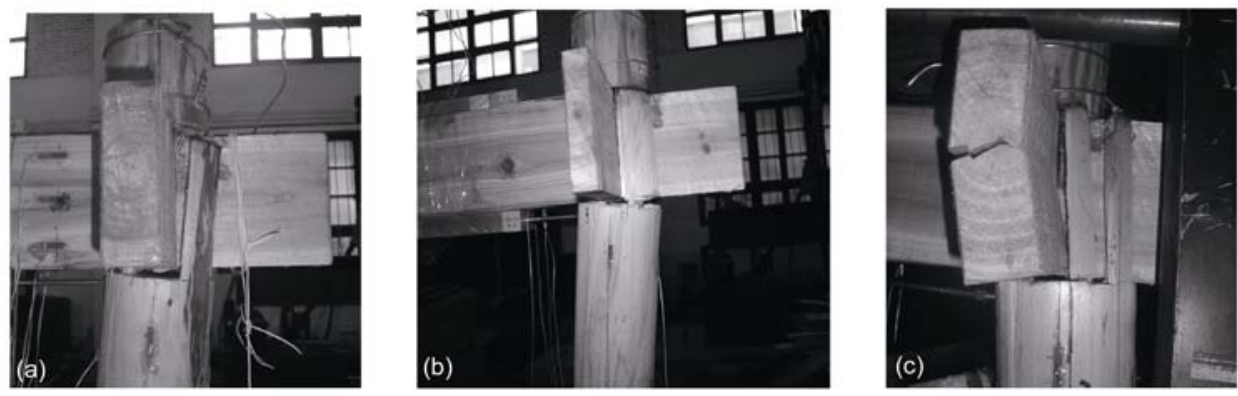

图 4 十字䈐头榫节点破坏形态

(a) KJ2-1 破坏形态; (b) KJ2-2 破坏形态; (c) KJ2-3 破坏形态
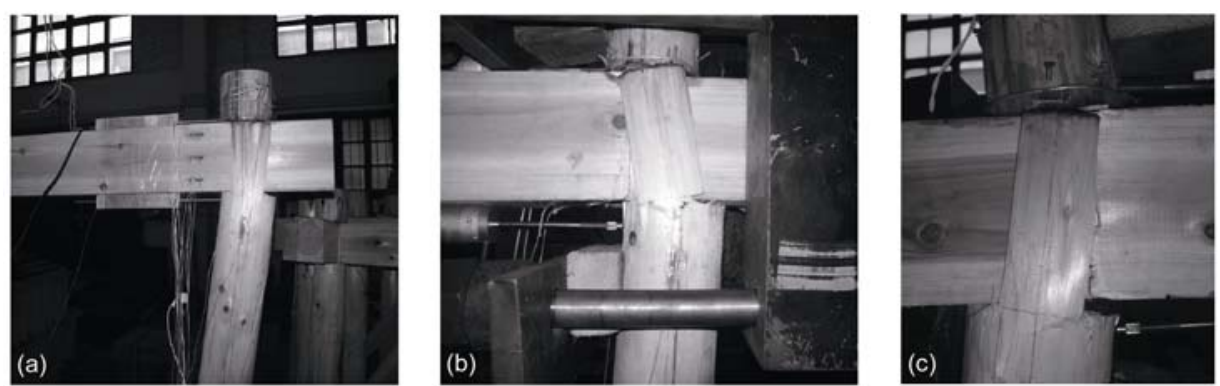

图 5 半榫节点破坏形态

(a) KJ3-1 破坏形态; (b) KJ3-2 破坏形态; (c) KJ3-3 破坏形态

象看, 其破坏过程先是榫头挤紧发出吱吱声, 由于上 部压力, 馒头榫梁头无法变形, 只能呈 $\mathrm{S}$ 形扭曲, 梁 柱交接处会出现局部承压破坏, 当荷载增加到一定 程度后, 梁头可以变形, 并伴随馒头榫弯曲, 随后很 快到达破坏阶段, 馒头榫折榫破坏. 增加榫的宽度可 以延后破坏, 增加长度反而会提前破坏. 馒头榫构架 的极限水平位移为 140 180 mm. 图 6 为馒头榫节点 的最终破坏形态.

\section{4 试验结果}

\section{1 $M-\theta$ 滞回曲线}

为了得到各典型榫卯节点的转角刚度特征, 必
须首先了解各榫卯节点的 $M-\theta$ 曲线. 本文结合 $P-\Delta$ 滞 回曲线和位移计所测得的转角信息, 得到各榫卯节 点的 $M-\theta$ 曲线, 如图 7 所示.

从图 7 可以总结出各典型榫卯节点滞回曲线的 一些特点.

（i ）当施加的水平荷载较小时, 节点刚度也较 小, 系统接近于机构, 其 $M-\theta$ 滞回曲线位于第二、四 象限, 为沿 $y$ 轴镜像的反 $\mathrm{S}$ 形, 这部分图形为“虚”滞 回曲线; 当施加的水平荷载较大时, 节点通过充分接 触、摩擦、咬合等作用, 系统开始耗能, $M-\theta$ 滞回曲线 基本呈 $Z$ 形. 对于燕尾榫木构，水平位移约 $120 \mathrm{~mm}$ 左右时, 榫卯节点半刚性特征明显; 对于十字䈐头榫 木构, 水平位移约 $120 \mathrm{~mm}$ 左右时, 榫卯节点半
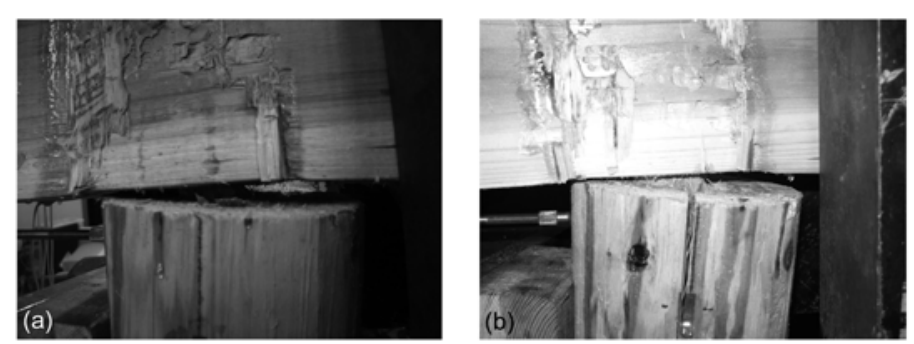

图 6 馒头榫节点破坏形态

(a) KJ4-1 破坏形态; (b) KJ4-2 破坏形态; (c) KJ4-3 破坏形态

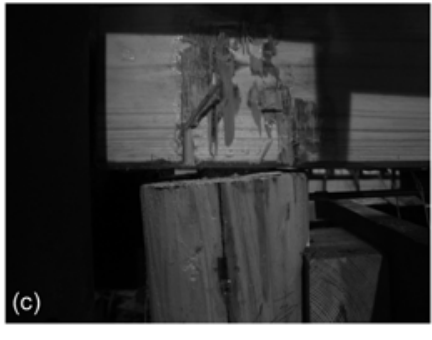

(c) 
淳庆等: 中国南方传统木构建筑典型榫卯节点抗震性能试验研究
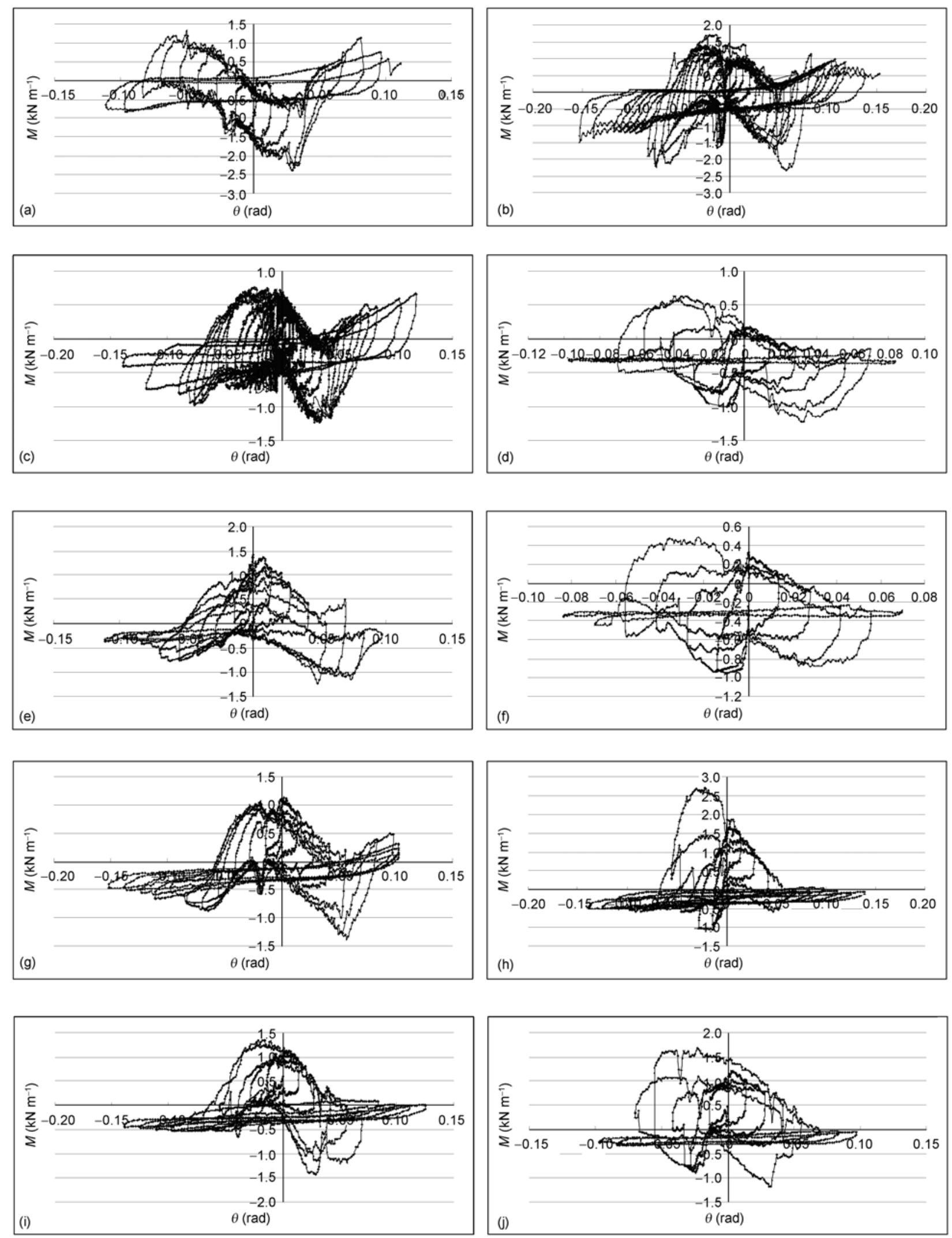

1158 

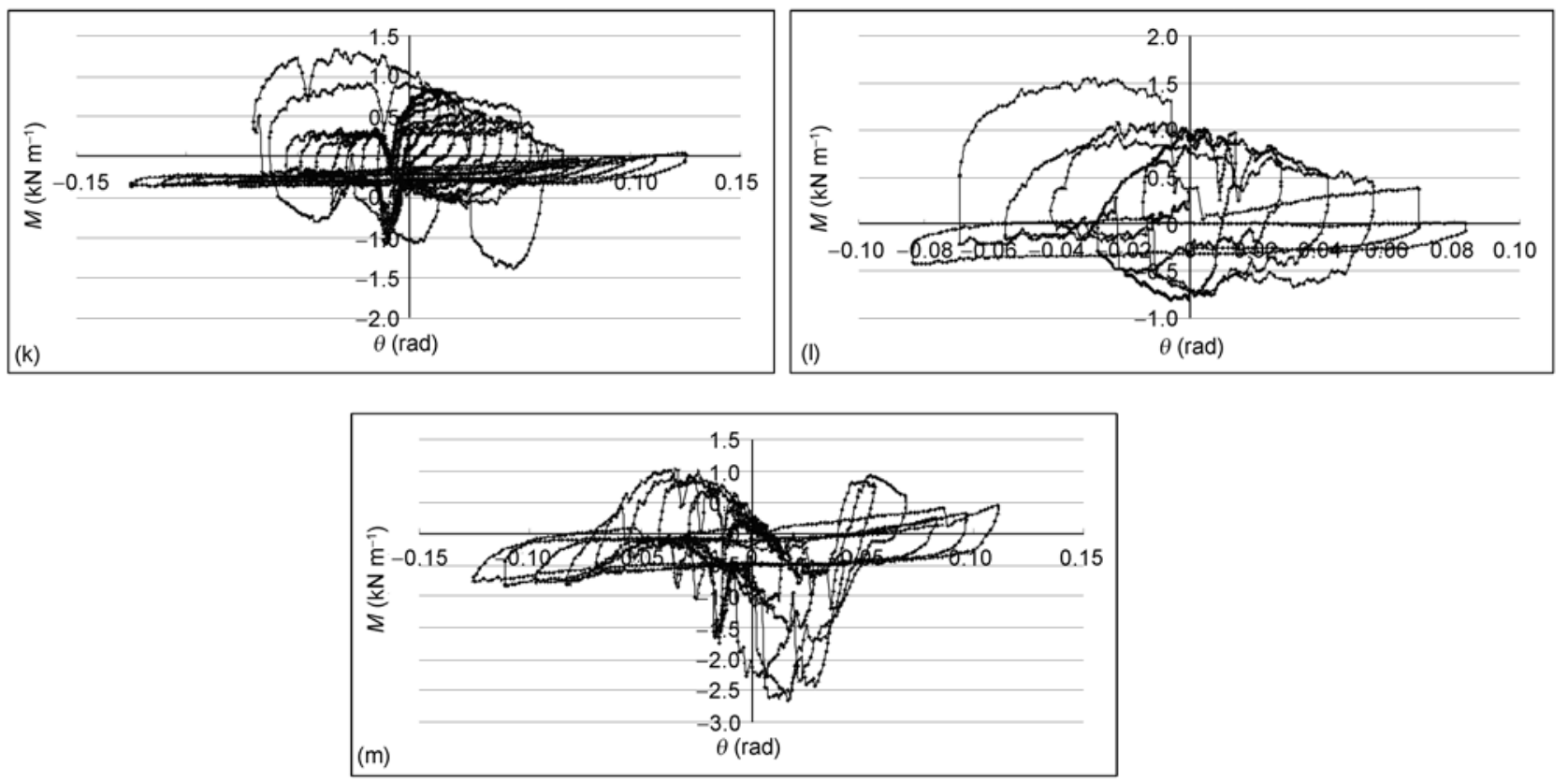

图 7 各典型榫卯节点的 $\boldsymbol{M}-\boldsymbol{\theta}$ 滞回曲线

(a) KJ1-1; (b) KJ1-2; (c) KJ1-3; (d) KJ2-1; (e) KJ2-2; (f) KJ2-3; (g) KJ3-1; (h) KJ3-2; (i) KJ3-3; (j) KJ4-1; (k) KJ4-2; (1) KJ4-3; (m) KJ5

刚性特征明显; 对于半榫木构, 水平位移约 $100 \mathrm{~mm}$ 左右时，榫卯节点半刚性特征明显; 对于馒头榫木 构, 水平位移约 $120 \mathrm{~mm}$ 左右时, 榫卯节点半刚性特 征明显.

(ii) 对于抗侧刚度而言, 燕尾榫 $>$ 半榫 $>$ 十字䈨 头榫 $>$ 馒头榫; 对于地震耗能能力而言, 燕尾榫 $>$ 半 榫 $>$ 馒头榫 $>$ 十字䈐头榫.

\section{$4.2 M-\theta$ 骨架曲线}

通过对各典型榫卯节点的 $M-\theta$ 滞回曲线处理后 可得到 $M-\theta$ 骨架曲线, 进行总结分析后可以将典型 榫卯节点 $M-\theta$ 骨架曲线近似简化为图 8 所示的三折 线模型, 各阶段刚度值见表 2 , 表中 $\theta$ 值取自图 8 的骨 架曲线, $K$ 按以下 3 式计算:

\section{表 2 各典型榫卯节点三折线模型特征值计算结果}

\begin{tabular}{|c|c|c|c|c|c|c|c|}
\hline \multicolumn{2}{|c|}{ Type of specimen } & $K_{\theta 1}$ & $K_{\theta 2}$ & $K_{\theta 3}$ & $\theta_{y}$ & $\theta_{0}$ & $\theta_{u}$ \\
\hline \multirow{3}{*}{$\begin{array}{c}\text { Yanwei } \\
\text { mortise-tenon }\end{array}$} & $\mathrm{KJ} 1-1$ & 8.471 & 26.763 & -11.976 & 0.054 & 0.078 & 0.111 \\
\hline & KJ1-2 & 2.400 & 25.262 & -10.741 & 0.050 & 0.083 & 0.141 \\
\hline & $\mathrm{KJ} 1-3$ & 3.936 & 14.484 & -7.972 & 0.048 & 0.076 & 0.118 \\
\hline \multirow{3}{*}{$\begin{array}{l}\text { Shizigutou } \\
\text { mortise-tenon }\end{array}$} & $\mathrm{KJ} 2-1$ & 0.647 & 3.597 & -6.260 & 0.045 & 0.059 & 0.082 \\
\hline & $\mathrm{KJ} 2-2$ & 7.350 & 1.115 & -3.359 & 0.020 & 0.040 & 0.090 \\
\hline & $\mathrm{KJ} 2-3$ & 0.969 & 2.121 & -3.168 & 0.036 & 0.046 & 0.070 \\
\hline \multirow{3}{*}{$\begin{array}{c}\text { Ban } \\
\text { mortise-tenon }\end{array}$} & $\mathrm{KJ} 3-1$ & 3.396 & 7.491 & -6.607 & 0.054 & 0.100 & 0.139 \\
\hline & $\mathrm{KJ} 3-2$ & 1.083 & 2.830 & -3.968 & 0.038 & 0.077 & 0.138 \\
\hline & $\mathrm{KJ} 3-3$ & 2.004 & 3.034 & -0.800 & 0.024 & 0.100 & 0.125 \\
\hline \multirow{3}{*}{$\begin{array}{c}\text { Mantou } \\
\text { mortise-tenon }\end{array}$} & KJ4-1 & 1.078 & 2.259 & -1.518 & 0.021 & 0.064 & 0.097 \\
\hline & KJ4-2 & 1.505 & 2.288 & -3.800 & 0.043 & 0.123 & 0.125 \\
\hline & KJ4-3 & 5.847 & 1.564 & -1.457 & 0.027 & 0.075 & 0.084 \\
\hline $\begin{array}{l}\text { Dropping Yanwei } \\
\text { mortise-tenon }\end{array}$ & KJ5 & 6.095 & 12.718 & -5.079 & 0.057 & 0.087 & 0.111 \\
\hline
\end{tabular}

Note: The unit of rotational stiffness is $\mathrm{kN} \cdot \mathrm{m}$ and the unit of rotation angle is rad. In the table, the stiffness and the angles were obtained according to $1 / 2$ scale models 


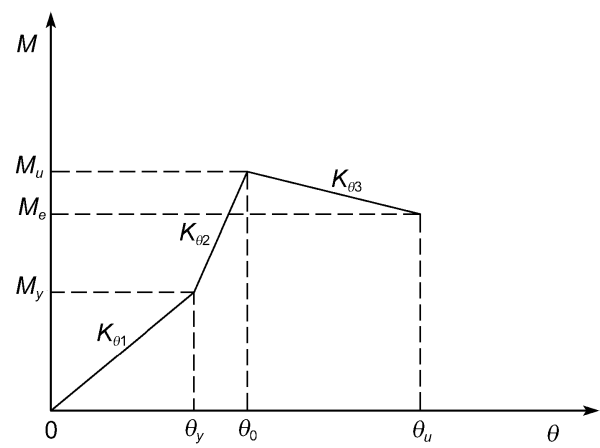

图 8 榫卯节点 $M-\theta$ 骨架曲线(三折线模型)

$$
\begin{gathered}
K_{\theta 1}=\frac{M_{y+}-M_{y-}}{\theta_{y+}-\theta_{y-}}, \\
K_{\theta 2}=\left(\frac{M_{u+}-M_{y+}}{\theta_{0+}-\theta_{y+}}+\frac{M_{y-}-M_{u-}}{\theta_{y-}-\theta_{0-}}\right) / 2, \\
K_{\theta 3}=\left(\frac{M_{u+}-M_{0+}}{\theta_{u+}-\theta_{0+}}+\frac{M_{e-}-M_{0-}}{\theta_{0-}-\theta_{u-}}\right) / 2 .
\end{gathered}
$$

各典型榫卯节点半刚性计算模型可以写成:

$$
M=\left\{\begin{array}{cc}
K_{\theta 1} \theta, & \theta \leqslant \theta_{y}, \\
K_{\theta 1} \theta_{y}+K_{\theta 2}\left(\theta-\theta_{y}\right), & \theta_{y} \leqslant \theta \leqslant \theta_{0}, \\
K_{\theta 1} \theta_{y}+K_{\theta 2}\left(\theta_{0}-\theta_{y}\right)+K_{\theta 3}\left(\theta-\theta_{0}\right), & \theta_{0}<\theta \leqslant \theta_{u},
\end{array}\right.
$$

式中, 各阶段特征值 $K_{\theta 1}, K_{\theta 2}, K_{\theta 3}, \theta_{y}, \theta_{0}$ 根据表 2 取值.

\section{5 结语}

本文通过对中国南方传统木构建筑中典型榫卯 节点的模型试验，研究了典型榫印节点的破坏特征、 滞回曲线、骨架曲线、转角刚度和抗震性能, 得到以 下主要结论.

(i)各典型榫卯构架在水平荷载作用下的最终破 坏均发生在榫卯节点部位. 燕尾榫(包括下落式燕尾 榫)最终破坏形态为拔榫破坏, 在各作法中, 加长型 燕尾榫破坏最晚, 变窄型次之, 标准型最先破坏. 燕 尾榫构架的极限水平位移为 160 220 mm; 十字䈐头 榫最终破坏形态为榫卯根部破坏，减小梁榫的宽度 或增设销钉可以延后破坏，十字箍头榫构架的极限 水平位移为 100 160 mm; 半榫最终破坏形态为印口 折断, 增加梁宽或减少梁榫头长度不会显著改变破 坏阶段，半榫构架的极限水平位移为 $160 \sim 180 \mathrm{~mm}$; 馒头榫最终破坏形态为榫头折断破坏, 增加榫的宽 度可以延后破坏, 增加长度反而会提前破坏, 馒头榫 的极限水平位移为 $140 \sim 180 \mathrm{~mm}$.

(ii)对于抗侧刚度而言, 燕尾榫 $>$ 半榫 $>$ 十字箍头 榫>馒头榫; 对于地震耗能能力而言, 燕尾榫>半榫> 馒头榫>十字筢头榫.

(iii) 将各典型榫卯节点(燕尾榫、十字筷头榫、半 榫、馒头榫)的 $M-\theta$ 骨架曲线简化为三折线模型, 并 计算了各阶段特征刚度, 试验结果可供分析南方传 统木构建筑的弹塑性抗震性能和构架节点破坏先后 顺序时参考使用, 但还需通过更多的试验研究来验 证和完善.

\section{参考文献}

1 方东平, 俞茂宏, 宫本裕, 等. 木结构古建筑结构特性的计算研究. 工程力学, 2001, 18: 137-144

2 方东平, 俞茂宏, 宫本裕, 等. 木结构古建筑结构特性的实验研究. 工程力学, 2000, 17: 75-83

3 姚㑆, 赵鸿铁, 葛鸿鹏. 古建木结构榫卯连接特性的试验研究. 工程力学, 2006, 23: 168-173

4 薛建阳, 赵鸿铁, 张鹏程. 中国古建筑木结构模型的振动台试验研究. 土木工程学报, 2004, 37: 6-11

5 高大峰. 中国木结构古建筑的结构及其抗震性能研究. 博士学位论文. 西安: 西安建筑科技大学, 2007

6 高大峰, 赵鸿铁, 薛建阳, 等. 中国古建木构架在水平反复荷载作用下变形及内力分析. 世界地震工程, 2003, 19: 9-14

7 高大峰, 赵鸿铁, 薛建阳. 木结构古建筑中斗栱与榫卯节点的抗震性能试验研究. 自然灾害学报, 2008, 17: 58-64

8 葛鸿鹏. 中国古代木结构建筑榫卯加固抗震试验研究. 硕士学位论文. 西安：西安建筑科技大学, 2005

9 谢启芳. 中国木结构古建筑加固的试验研究及理论分析. 博士学位论文. 西安: 西安建筑科技大学, 2007

10 谢启芳, 赵鸿铁, 薛建阳, 等. 中国古建筑木结构榫卯节点加固的试验研究. 土木工程学报, 2008, 41: 28-34

11 Villar J R, Guaita M, Vidal P, et al. Analysis of the stress state at the cogging joint in timber structures. Biosyst Eng, 2007, (1): 79-90

12 Ayala D F, Tsai P H. Seismic vulnerability of historic Dieh-Dou timber structures in Taiwan. Eng Struct, 2008, (30): 2101-2113 